\title{
The Effect of using Mixed Initiator Systems on the Efficiency of Photopolymerization of Dental Resins
}

\author{
Miguel G. Neumann, ${ }^{*, a}$ Carla C. Schmitt, ${ }^{a}$ Ivo C. Correa ${ }^{b}$ and Beatriz E. Goi ${ }^{a}$ \\ ${ }^{a}$ Instituto de Química de São Carlos, Universidade de São Paulo, CP 780, 13560-970 São Carlos-SP, Brazil \\ ${ }^{b}$ Faculdade de Odontologia, Universidade Federal do Rio de Janeiro, Rio de Janeiro-RJ, Brazil
}

\begin{abstract}
Foi realizado um estudo para determinar a eficiência da utilização simultânea dos fotoiniciadores fenilpropanodiona (PPD) e canforquinona (CQ) para a polimerização de polímeros acrílicos e avaliar possíveis mecanismos que levem à sinergia ou antagonismo. Foi encontrado que as eficiências de ambos iniciadores usados individualmente são maiores que a da mistura, indicando que quando os iniciadores são usados simultaneamente há uma transferência de energia do iniciador mais eficiente (CQ) para o menos eficiente (PPD). Também, não foi encontrada nenhuma evidência de reação entre a amina presente na formulação da CQ e o PPD no estado excitado.
\end{abstract}

A study was performed in order to determine the efficiency of the simultaneous use of the photoinitiators phenylpropanedione (PPD) and camphorquinone (CQ) in the polymerization of acrylic polymers and evaluate possible mechanisms leading to synergism or antagonism. It was found that efficiencies of both initiators taken individually are higher than that of their mixture, indicating that when both dyes are used simultaneously there will be an energy transfer from the more efficient initiator (CQ) to the less efficient one (PPD). Also, there was no proof of any reaction between the amine present in the CQ formulation and the PPD excited state.

Keywords: photoinitiators, photopolymerization, mixed initiator systems, synergy

\section{Introduction}

Light-induced polymerization systems are used as permanent restorative dental resin composites in dentistry. Initially, these systems can be divided into two categories, according to the light source: UV or visible light. ${ }^{1}$ Nowadays, UV sources are not longer used due to negative biological effects. ${ }^{2}$

In recent years several academic and commercial research laboratories tried to develop new photocurable dental resins (composed, mainly, of organic monomers, inorganic fillers, a photosensitizer, and a co-initiator). ${ }^{3-7}$ Among them, the photosensitizer is the most important component since it initiates the photopolymerization of the resin composite. Camphorquinone (CQ) is widely used as photosensitizer for visible light curing, ${ }^{8-10}$ although it presents some drawbacks like low polymerization efficiency, toxicity, and yellowing due to the presence of an amine-derived co-initiator. The low polymerization efficiency of CQ results in low mechanical properties of

\footnotetext{
*e-mail: neumann@iqsc.usp.br
}

the resin composite, as well as possible toxic effects to the human body from residual monomers.

In recent years several works have dealt with the simultaneous use of two or more photoinitiators in photopolymerizable formulations used in dentistry. In many cases, an increase of the polymerization efficiency was observed, and this effect was defined as synergy, as the reaction rate was found to be larger than that observed when using the individual initiators separately. ${ }^{9}$ Phenylpropanedione (PPD) is a recently proposed visiblelight photosensitizer for dental resins, showing larger photopolymerization efficiency than CQ and producing resins with higher surface hardness. ${ }^{1}$ Its use simultaneously with CQ was reported to induce an increase of the polymerization efficiency and improve the quality of the final resin. ${ }^{11}$ Differences in the photoinitiators chemistry of both species, CQ and PPD, influence the efficiency of polymerization when cured by quartz-tungsten-halogen (QTH) or light emitting diode light sources. ${ }^{10}$ In order to determine the mechanisms involved in this effect, a study of systems containing Camphorquinone (CQ) and Phenylpropanedione (PPD) was undertaken 


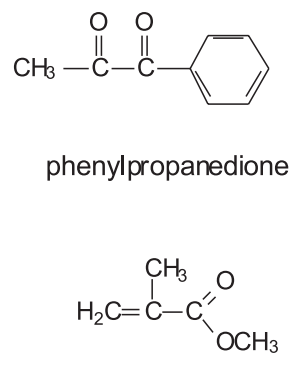

methyl methacrylate

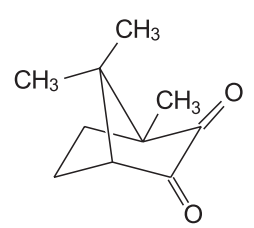

camphorquinone

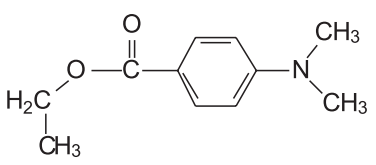

ethyl 4-dimethylaminobenzoate
Scheme 1. Photoinitiators and chemicals used throughout this work.

\section{Experimental}

\section{Materials}

The monomer, methyl methacrylate (Merck) was distilled from ice bath at reduced pressure in the presence of hydroquinone, washed with $5 \% \mathrm{NaOH}$ in water and dried over $\mathrm{CaCl}_{2}$. 1-Phenyl-1,2-propanedione (PPD), camphorquinone (CQ), and ethyl 4-dimethylaminobenzoate, (EDB) were purchased from Aldrich and used without further purification.

\section{Photopolymerization procedure}

The kinetics of the light induced polymerization of MMA (pure monomer, $c a .9 \mathrm{~mol} \mathrm{~L}^{-1}$ ) in the presence of photoinitiators systems (PPD, CQ-EDB and PPD-CQ/ EDB) were followed in a dilatometer. ${ }^{11,12}$ The solution was thoroughly deoxygenated by bubbling oxygen-free nitrogen for $40 \mathrm{~min}$. The dilatometer consisted of two capillaries (internal diameter $0.18 \mathrm{~cm}$ ) attached to a cylindrical reaction vessel (internal diameter $2.2 \mathrm{~cm}$, volume $8.5 \mathrm{ml}$ ), which was placed in a constant temperature bath $\left(25^{\circ} \mathrm{C}\right)$ in front of the irradiation source. The reaction cell was placed in front of a 200 W Hg (Xe) lamp in an Oriel Universal Arc Lamp source. A $395 \mathrm{~nm}$ cut-off filter was placed between the lamp and the reaction cell to eliminate the uv-radiation.

Polymerization rates $\left(R_{p}\right)$ were calculated using equation $1^{13}$

$R_{p}=\frac{\Delta V}{F . f . t}[\mathrm{MMA}]\left(\mathrm{mol} \mathrm{L}^{-1} \mathrm{~s}^{-1}\right)$

where $\Delta \mathrm{V}$ is the volume contraction in the capillary (measured with a cathetometer) at time $t, f$ the volume fraction of monomer MMA in the solution, $F$ the volume contraction related to the densities of polymer and monomer solution, $F=\left[\left(d_{p}-d_{m}\right) / d_{p}\right]$, and $d_{p}$ and $d_{m}$ being the densities of the polymer and the monomer, respectively.

Actinometry was performed using the ferrioxalate/ phenanthroline sensitizer. As the quantum efficiency of this actinometer $(\phi)$ depends on the irradiating wavelength, appropriate $\phi$-values were used for different wavelength ranges, i.e., 400 to $436 \mathrm{~nm}(\phi=1.00), 437$ to $468 \mathrm{~nm}$ $(\phi=0.85), 469$ to $500 \mathrm{~nm}(\phi=0.58) .{ }^{14}$

The polymerization quantum yields of $\left(\Phi_{\mathrm{p}}\right)$ were calculated using

$\Phi_{p}=\frac{R_{p}}{n_{T}}$

were $n_{T}$ is the photon flow in Einstein $\mathrm{s}^{-1}$.

\section{Photochemical measurements}

Static fluorescence quenching experiments were carried out at room temperature using a Hitachi F-4500 spectrofluorimeter on air-equilibrated solutions using ethyl acetate as a solvent, due to its properties being quite similar to those of MMA. CQ was excited at $470 \mathrm{~nm}$ and the emission was determined at the maximum of the emission peak. Absorption spectra were measured on a Hitachi U-2000 spectrophotometer.

\section{Results and Discussion}

Park et al. ${ }^{11}$ found that the use of both initiators together would increase the rate of polymerization in dentistry formulations. This effect can be, ideally, achieved in three different ways: $i$ ) an increase of the amount of light absorbed by the mixture when both dyes are present, taking into account that their absorption spectra are different; $i i$ ) the onset of a new mechanism that accelerates the reaction rate; iii) an energy transfer from the less efficient dye to the more efficient one, rendering a higher reaction yield.

Three different initiating systems containing CQ and PPD were used. In all the total concentration of dye was $5 \times 10^{-4} \mathrm{~mol} \mathrm{~L}^{-1}$. Two of them were the pure initiators, i.e., $\mathrm{PPD}$ and $\mathrm{CQ}$ (in the presence of $\mathrm{EDB}$ as co-initiator) and the third, a mixture of CQ $\left(4 \times 10^{-4} \mathrm{~mol} \mathrm{~L}^{-1}\right)$ and PPD $\left(1 \times 10^{-4} \mathrm{~mol} \mathrm{~L}^{-1}\right)$. The absorption spectra of these solutions are shown in Figure 1. It can be seen that the addition of PPD to CQ will increase the absorption in the blue region. Therefore, depending on the emission output of the lamps used in the process, the amount of photons absorbed by the mixture is larger and should induce the formation of more initiating radicals than when just one dye is used. 


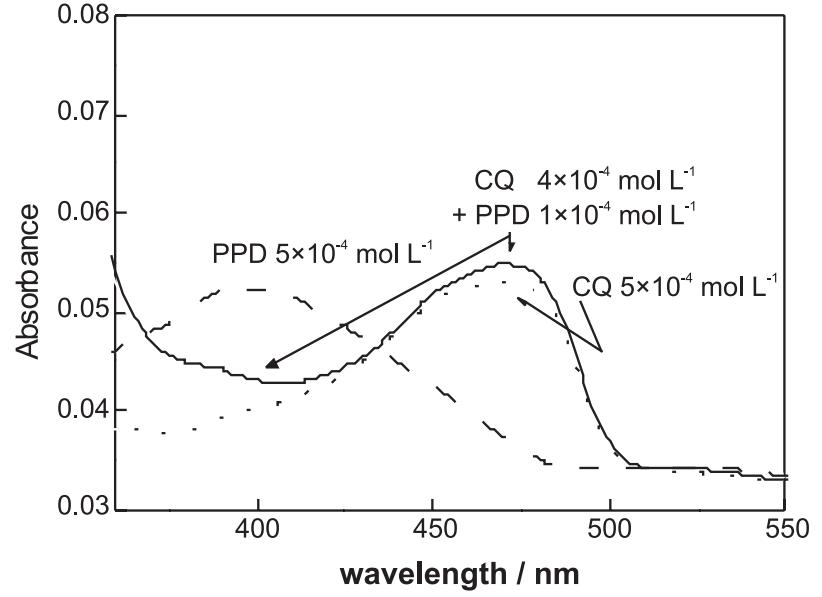

Figure 1. Absorption spectra of the photoinitiators and their mixture.

MMA was used as a standard to determine the photopolymerization quantum yields, as the experimental determination of the polymerization kinetics of this monomer is easier. The observed effects due to the higher or lower concentration of initiating free radicals, can then be extended to the photopolymerization of other monomers. Additionally, the polymerization of this monomer can be performed in bulk, so that no interference of solvent effects will occur.

The photopolymerization rates of the systems used were measured dissolving the initiators in pure MMA and irradiating with a Xe arc lamp. The kinetic behaviour of all three systems is shown in Figure 2. As can be seen the polymerization rate is faster when initiated with CQ as when using PPD, and the addition of PPD to CQ leads to an intermediate reaction rate.

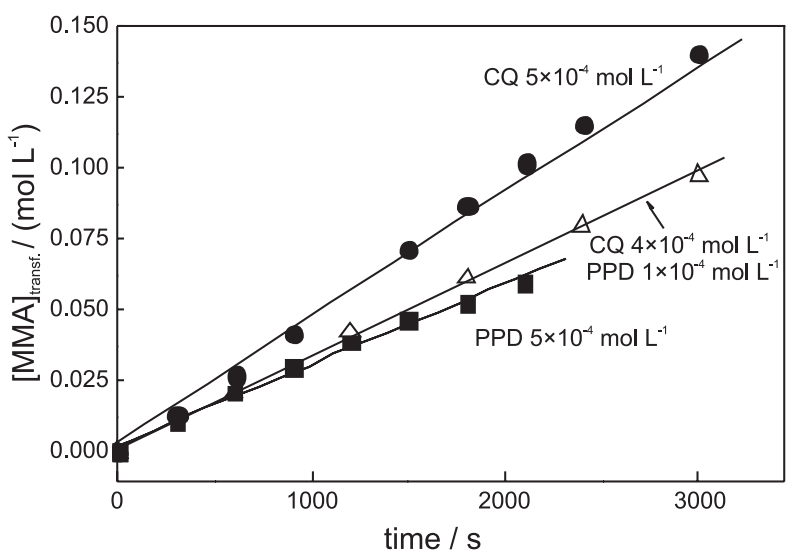

Figure 2. Polymerization kinetics of MMA photoinitiated by PPD, CQ and its mixture.

As shown in a previous report, in order to assess the efficiency of the photopolymerization process, it is
Table 1. Photopolymerization of MMA in the presence of three initiating systems: polymerization rates (Rp), photon flux and quantum yields $\left(\Phi_{\mathrm{p}}\right)$

\begin{tabular}{lccc}
\hline $\begin{array}{l}\text { Photoinitiator/ } \\
\left.(\mathrm{mol} \mathrm{L})^{-1}\right)\end{array}$ & $\begin{array}{c}\mathrm{R}_{\mathrm{p} /} \\
\left(10^{-5} \mathrm{~mol}^{-1} \mathrm{~L} \mathrm{~s}^{-1}\right)\end{array}$ & $\begin{array}{c}\text { photon flux } \\
\text { Einstein/ } \\
\left(10^{-8} \mathrm{~s}^{-1}\right)\end{array}$ & $\begin{array}{c}\Phi_{\mathrm{p} /} \\
\left(\mathrm{mol} \mathrm{Einstein}^{-1}\right)\end{array}$ \\
\hline $\operatorname{PPD}\left(5 \times 10^{-4}\right)$ & 2.86 & 7.6 & 376 \\
$\mathrm{CQ}\left(5 \times 10^{-4}\right)$ & 4.70 & 11.2 & 420 \\
$\operatorname{PPD}\left(1 \times 10^{-4}\right)+$ & 3.25 & 9.5 & 342 \\
$\mathrm{CQ}\left(4 \times 10^{-4}\right)$ & & & \\
\hline
\end{tabular}

necessary to deal with polymerization quantum yields, rather then with the reaction rates. ${ }^{13}$ The rate constants of the MMA photopolymerization in the presence of all three initiating systems are shown in Table 1, together with the amount of absorbed photons, and the polymerization quantum yields.

It is noteworthy to notice that the quantum yield for the polymerization initiated by the mixture of the dyes is lower than that of any of both dyes used separately. Assuming that both dyes initiate separately, and that the quantum yield of the mixture can be obtained from the individual contributions of each initiator, the ideal photopolymerization quantum yield for the mixture should be

$\Phi_{\mathrm{M}}=\mathrm{X}_{\mathrm{PPD}} \times \Phi_{\mathrm{PPD}}+\mathrm{X}_{\mathrm{CQ}} \times \Phi_{\mathrm{CQ}}$

where $\Phi_{M}$ is the quantum yield for the photopolymerization initiated by the mixture, and $\Phi_{\mathrm{PPD}}$ and $\Phi_{\mathrm{CQ}}$ are the quantum yields for the photopolymerization initiated PPD and $\mathrm{CQ}$, respectively. $\mathrm{X}_{\mathrm{PPD}}$ and $\mathrm{X}_{\mathrm{CQ}}$ are the molar fractions of the initiators PPD and CQ. Using equation 3 a value of 411 is obtained for $\Phi_{\mathrm{M}}$. The corresponding experimental value shown in Table 1 is 342, indicating that rather than a synergistic effect, the addition of the second dye (PPD) makes the reaction less efficient.

This effect can be attributed to the fact that there is an efficient quenching of the excited camphorquinone by PPD

$\mathrm{PPD}+{ }^{1} \mathrm{CQ} \rightarrow{ }^{1} \mathrm{PPD}+\mathrm{CQ}$

as shown in Figure 3. The Stern-Volmer constant for this process is $273 \mathrm{~mol}^{-1} \mathrm{~L}$, which taken together with the reported lifetime for camphorquinone singlet $(18 \mathrm{~ns})^{15}$ gives a quenching rate constant of $1.52 \times 10^{10} \mathrm{~mol}^{-1} \mathrm{~L} \mathrm{~s}^{-1}$. This rate is of the order of the diffusional limit in ethyl acetate. 


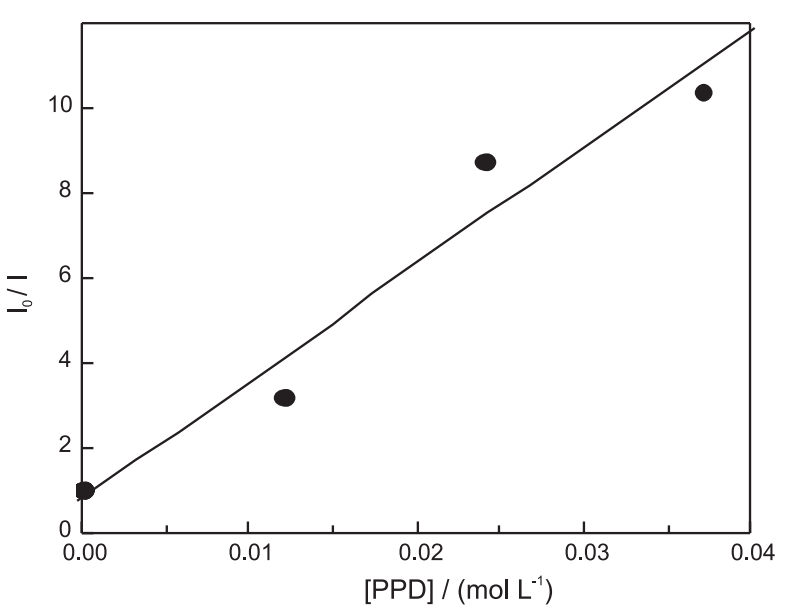

Figure 3. Quenching of the fluorescence of Camphorquinone by PPD in ethyl acetate.<smiles>CC12CCC(C(=O)C1=O)C2(C)C</smiles><smiles>[R]C[N+](C)(C)[O+]=C(C)C(C)CC</smiles>
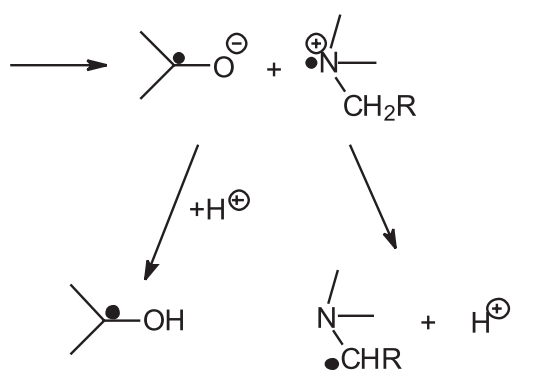

In addition, these results also help to rule out the onset of an alternative mechanism for the photoinitiation by PPD. As demonstrated earlier, the polymerization photoinitiated by CQ only happens in the presence of an amine acting as co-initiator whereas the initiation by PPD is considered to be a mere $\mathrm{C}-\mathrm{C}$ scission

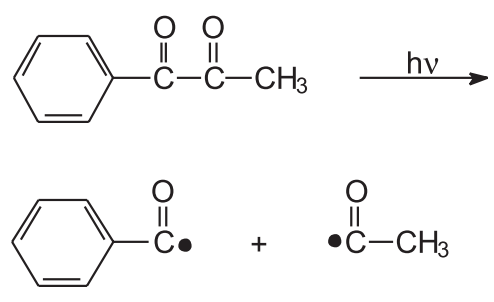

In principle, the presence of an amine, as in the CQ/ PPD mixture, could promote a secondary reaction between the amine and the radicals forming more efficient initiating amino radicals

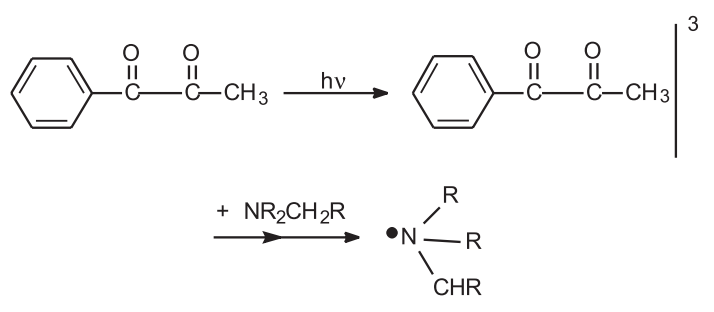

The fact that there is no increase in the efficiency when the co-initiator amine EDB is present means that reaction 7 does not occur in the system.

\section{Conclusions}

The simultaneous use of the photopolymerization initiators CQ and PPD does not lead to a synergistic increase in the polymerization efficiency, although there might be an increase in the degrees of conversion due to the broader absorption band of the mixture of dyes. On the contrary, the polymerization quantum yield when using the mixture is lower than for the individual initiators used alone. This inhibition effect can be traced to an efficient quenching of the more efficient dye (CQ) by the less efficient one (PPD). An increase in the concentration of the dye should be preferred over the mixture with a second dye, when the aim is to enhance the photopolymerization efficiency.

\section{Acknowledgments}

Financial support by FAPESP, Brazil (Proc. 03/07770-4) and CNPq (Proc. 471310/2006-9) is gratefully acknowledged. Beatriz E. Goi also thanks FAPESP for a post-doctoral fellowship.

\section{References}

1. Sun, G. J.; Chae, K. H.; Polymer 2000, 41, 6205.

2. Rueggeberg, F. A.; J. Prosthet. Dent. 2002, 87, 364.

3. Peutzfeltdt, A.; Asmussen, E.; Acta Odont. Scand. 1989, 47, 229.

4. Peutzfeldt, A.; Eur. J. Oral Sci. 1997, 105, 97.

5. Nie, J.; Lindén, L. -A.; Rabek, J. F.; Ekstrand, J.; Angew. Makromol. Chem. 1998, 257, 47.

6. Sionkowska, A.; Kaminska, A.; Linden, L.-A.; Rabek, J. E.; Polym. Bull. 1999, 43, 349.

7. Chung, C.-M.; Kim, J.-G.; Kim, M.-S.; Kim, K.-M.; Kim, K.-N.; Dental Mater. 2002, 18, 174.

8. Teshima, W.; Nomura, Y.; Tanaka, N.; Urabe, H.; Okazaki, M.; Nahara, Y.; Biomaterials 2003, 24, 2097.

9. Park, Y.-J.; Chae, K.-H.; Rawls, K. R.; Dental Mater. 1999, 15, 120. 
10. Ogunyinka, A.; Palin, W. M.; Shortall, A. C.; Marquis, P. M.; Dental Mater. 2007, 23, 807.

11. Neumann, M. G.; Schmitt, C. C.; Ferreira, G. C.; Corrêa, I. C.; Dental Mater. 2006, 22, 576.

12. Neumann, M. G.; Schmitt, C. C.; Goi, B. E.; J. Photochem. Photobiol. A 2005, 174, 239.

13. Block, H.; Ledwin, A.; Taylor, A. R.; Polymer 1971, 12, 271.

14. Rabek, J. F.; Experimental Methods in Photochemistry and Photophysics. Part 2, Wiley Interscience: New York, 1982.
15. Allonas, X.; Fouassier, J.-P.; Angiolini, L.; Caretti, D.; Helv. Chim. Acta 2001, 84, 2577.

Received: April 4, 2008 Web Release Date: August 29, 2008

FAPESP helped in meeting the publication costs of this article. 